\title{
Formation of Gas Vesicles in Phosphorus-limited Cultures of Microcystis aeruginosa
}

\author{
By JACCO KROMKAMP, ${ }^{*}+$ ANDIEN VAN DEN HEUVEL \\ AND LUUC R. MUR \\ Department of Microbiology, University of Amsterdam, Nieuwe Achtergracht 127, \\ 1018 WS Amsterdam, The Netherlands
}

(Received 22 December 1988; revised 3 March 1989; accepted 28 March 1989)

\begin{abstract}
The formation of gas vesicles in samples taken from phosphorus-limited cultures of Microcystis aeruginosa was studied after a phosphate pulse. A light period of at least $\mathrm{i} 0 \mathrm{~h}$ after the pulse was needed before gas vesicles were synthesized de novo, and formation did not occur in the dark. The length of the light period correlated with the increase in gas vacuolation. When samples were subjected to $5 \mathrm{~h}$ light periods at different times after the addition of phosphate, formation of gas vesicles was only observed when the light period started at least $5 \mathrm{~h}$ after the addition of phosphate. Gas vesicle formation was saturated at a photon flux density of approximately $50 \mu \mathrm{mol} \mathrm{m}^{-2} \mathrm{~s}^{-1}$. Synthesis of gas vesicles was not detected when the cultures were treated with chloramphenicol, rifampicin or 3-(3,4-dichlorophenyl)- $N, N^{\prime}$-dimethylurea (DCMU); total gas vesicle volume did not decrease under these conditions, suggesting that turnover of gas vesicles occurs very slowly, if at all.
\end{abstract}

\section{INTRODUCTION}

Gas vesicles are found in phylogenetically different prokaryotes. They are hollow cylinders with conical caps and are composed entirely of protein (Walsby \& Buckland, 1969; Jones \& Jost, 1970; Konopka et al., 1977; Walker \& Walsby, 1983). Gas vesicles provide buoyancy if they occur in sufficient quantities. Gas vesicle protein may account for $8-16 \%$ of the total cell protein (Oliver \& Walsby, 1984; Konopka et al., 1987a, b; Kromkamp et al., 1988).

Regulation of gas vesicle synthesis is not well understood. The rate of gas vesicle synthesis was shown to be dependent on growth rate in light-limited continuous cultures of Aphanizomenon flos-aquae PCC 7905 (Kromkamp et al., 1986), but was independent of the growth rate in cultures grown under phosphorus limitation (Konopka et al., 1987a). In light-limited cultures of Microcystis aeruginosa AK1, however, the gas vesicle content remained constant at all growth rates (Kromkamp et al., 1988). The results of Hayes \& Walsby (1984) implied that protein of collapsed gas vesicles is used in the formation of new vesicles. Waaland \& Branton (1969) and Lehmann \& Jost (1971) studied the kinetics of gas vesicle synthesis after their collapse in a strain of Nostoc muscorum (strain 172 of the Microgarden Culture Collection, Department of Botany, University of California, Berkeley, USA, according to Armstrong et al., 1983) and in $M$. aeruginosa NRC-1. They showed that the number of initiation sites for assembly was limited and that the conical caps were assembled before elongation of the cylindrical midsection occurred. Similar results were obtained by Konopka et al. (1975) for the heterotrophic bacterium Microcyclus aquaticus ATCC 27068 strain S1 (subsequently placed in the genus Ancylobacter: Raj, 1983). In a previous study (Konopka et al., 1987 b) we demonstrated that formation of gas vesicles occurred after enrichment with phosphate in a phosphorus-limited culture of $\boldsymbol{M}$.

† Present address: Department of Botany, University of Bristol, Woodland Road, Bristol BS8 1UG, UK.

Abbreviations: RGV, relative gas vesicle content; DCMU, 3·(3,4-dichlorophenyl)- $N, N^{\prime}$-dimethylurea. 
aeruginosa. Formation of new gas vesicles occurred only in the light. Dark-incubated cultures regained buoyancy by catabolism of the polysaccharide ballast content.

In this paper we report further studies of gas vesicle formation in phosphorus-limited cultures of $M$. aeruginosa AK1.

\section{METHODS}

Culture conditions. Microcystis aeruginosa AK1 was isolated by A. Konopka (Department of Biological Sciences, Purdue University, USA) from Lake Mendota, Wisconsin. The organism was grown under a $5 \mathrm{~h}$ light:19 h dark cycle in 2-litre chemostat vessels as described by Kromkamp et al. (1986) at $20 \pm 0.5^{\circ} \mathrm{C}$, and sparged with compressed air at a rate of $60 \mathrm{l} \mathrm{h}^{-1}$ to keep the cells in suspension and to prevent $\mathrm{CO}_{2}$ limitation. The average irradiance in the culture was $110 \pm 20 \mu \mathrm{mol} \mathrm{m}^{-2} \mathrm{~s}^{-1}$. The culture medium was a modification (Konopka $e t$ al., $1987 \mathrm{~b}$ ) of medium A of Zehnder \& Hughes (1958). Phosphate $(2 \mu \mathrm{mol})$ was added to samples ( $100 \mathrm{ml})$ withdrawn from the steady-state cultures (allowing a two- to threefold increase in biomass). These samples were incubated at $20 \pm 1{ }^{\circ} \mathrm{C}$, sparged with compressed air and used for analyses. The irradiance during the incubations was $100-$ $150 \mu \mathrm{mol} \mathrm{m} \mathrm{m}^{-2} \mathrm{~s}^{-1}$.

Analyses. The gas vesicle content was measured in two ways: $(a)$ the relative gas vesicle content (RGV), which is the pressure-sensitive turbidity determined by pressure nephelometry (Walsby, 1973), divided by a parameter of biomass, either the protein content or the cell number (Kromkamp \& Mur, 1984); or (b) the absolute amount of gas vesicle space determined using a capillary compression tube (Walsby, 1982). As these latter values showed the same trends, only the RGV data are presented here.

Cell numbers were determined with a Coulter Counter Zb connected to a Coulter Channalyzer C1000.

Carbohydrate was determined on lyophilized samples by the anthrone method with D-glucose as standard, and protein was determined with the Folin reagent employing bovine serum albumin as standard, both according to Herbert et al. (1971).

\section{RESULTS}

\section{Effect of growth rate upon gas vesicle formation}

Samples from phosphate-limited cultures of $M$. aeruginosa AK 1, grown at three different dilution rates $\left(D=0.004 \mathrm{~h}^{-1}, 0.008 \mathrm{~h}^{-1}\right.$ and $\left.0.015 \mathrm{~h}^{-1}\right)$, were supplied with phosphate and incubated in the dark, or under continuous light, or subjected to a $5 \mathrm{~h}$ light period, in batch culture. Little or no increase in protein synthesis occurred at all growth rates if the cultures were kept in the dark after addition of phosphate (Fig. 1). In these cultures (as in those receiving $5 \mathrm{~h}$ of light) the carbohydrate to protein ratio dropped from $1 \cdot 1$ to 0.35 (not shown). The latter value is characteristic for a light limitation (Kromkamp et al., 1988). The cultures kept in continuous light after the phosphate pulse made more protein than cultures which only received $5 \mathrm{~h}$ of light (Fig. 1). Cell division did not occur in continuous light after the phosphate pulse in the culture grown at $D=0.004 \mathrm{~h}^{-1}$, whereas an increase in cell number was observed after $50 \mathrm{~h}$ in the culture grown at $D=0.008 \mathrm{~h}^{-1}$. The culture grown at $D=0.015 \mathrm{~h}^{-1}$ showed a significant increase in cell number $24 \mathrm{~h}$ after phosphate addition. Cell division did not occur in any of the cultures incubated in the dark or given the $5 \mathrm{~h}$ light period (Fig. 1). As expected, no gas vesicle formation occurred in the three cultures when they were kept in the dark after the phosphate pulse (Fig. 1). In continuous light, formation of gas vesicles was observed $50 \mathrm{~h}$ after the phosphate pulse in the culture grown at $D=0.004 \mathrm{~h}^{-1}$ and a small but significant $(P<0.05)$ increase was observed $24 \mathrm{~h}$ after addition of phosphate to the culture at $D=0.008 \mathrm{~h}^{-1}$ (Fig. 1). Both cultures showed an $80 \%$ increase in gas vesicle formation $50 \mathrm{~h}$ after the phosphate pulse. Of the cultures which received $5 \mathrm{~h}$ of light after the phosphate pulse, only that grown at $D=0.015 \mathrm{~h}^{-1}$ increased the relative gas vesicle content; the latter culture showed no increase under continuous illumination (Fig. 1) because synthesis of cell protein and assembly of new gas vesicles increased at the same rate. Since the culture with the highest growth rate responded relatively quickly by accelerating growth, whereas the culture with $D=0.004 \mathrm{~h}^{-1}$ showed essentially no growth response in the $50 \mathrm{~h}$ period after the phosphate pulse, all further experiments were performed at $D=0.004 \mathrm{~h}^{-1}$ to separate gas vesicle formation from growth effects. 


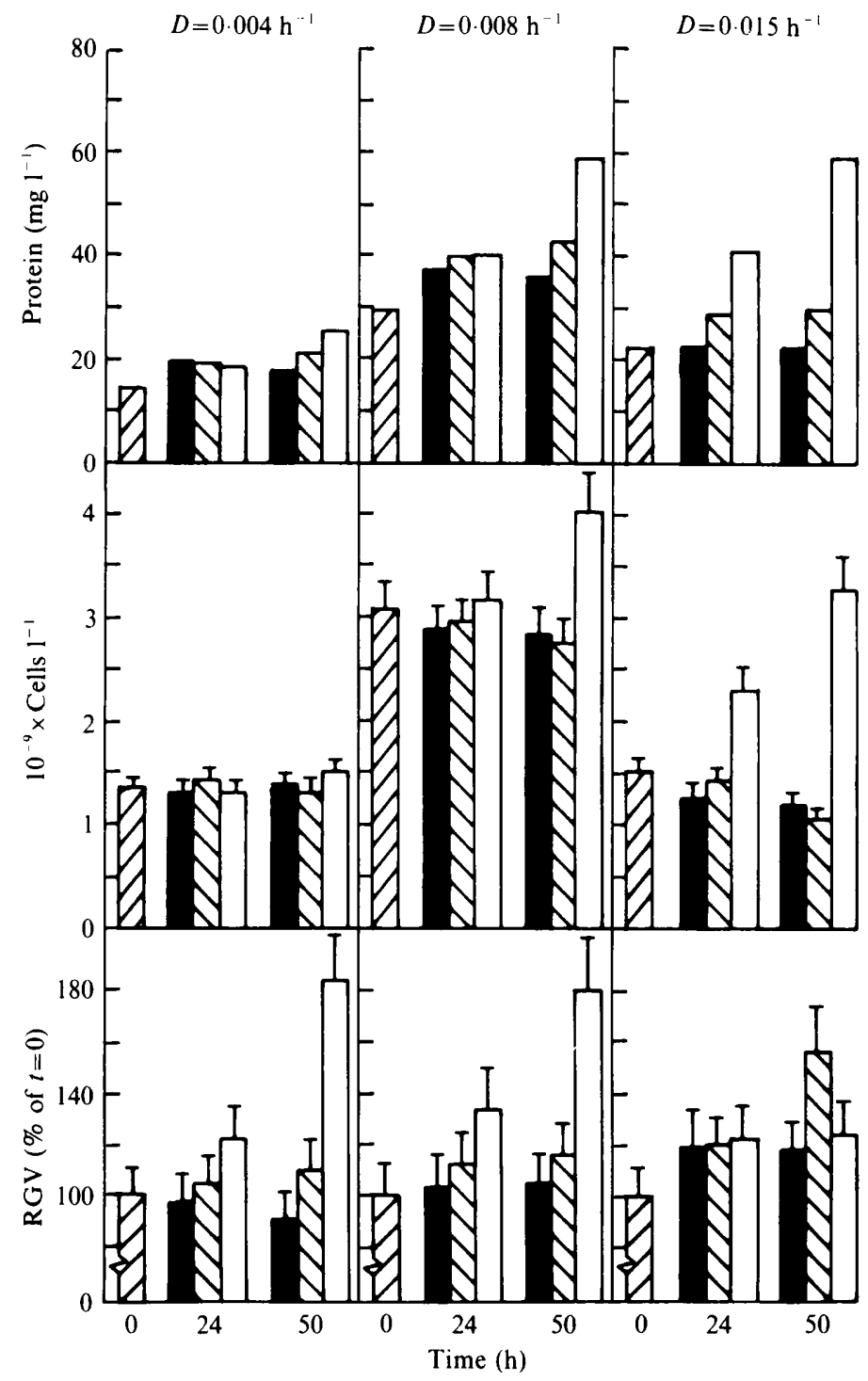

Fig. 1. Change in protein, cell numbers and relative gas vesicle volume (RGV, percentage of RGV at $t=0$ ) with time. Samples from phosphate-limited cultures of $M$. aeruginosa AK 1 grown with different dilution rates $(D)$ were given a phosphate pulse at zero time and incubated under the following conditions: $\square$, constant illumination; $\square$, dark; $\square$, illuminated for $5 \mathrm{~h}$ only; $\square$, values at zero time. The bars indicate the $95 \%$ confidence intervals. The protein concentrations are the means of duplicate samples; other values are calculated from three samples.

Influence of the length of the light period upon gas vesicle formation

Cultures receiving $0,2.5,5$ or $7.5 \mathrm{~h}$ of light following the phosphate pulse showed no significant formation of gas vesicles $(P<0.01$, linear regression analyses), whereas in the culture receiving $10 \mathrm{~h}$ of light there was a significant increase in gas vesicles (Fig. 2a). Although the extent to which new formation of gas vesicles occurred was rather variable between the different experiments, net gas vesicle formation occurred at all the light periods longer than $10 \mathrm{~h}$ (Fig. $2 b$ ). Linear regression analyses showed that the gas vesicle volume was positively related to 


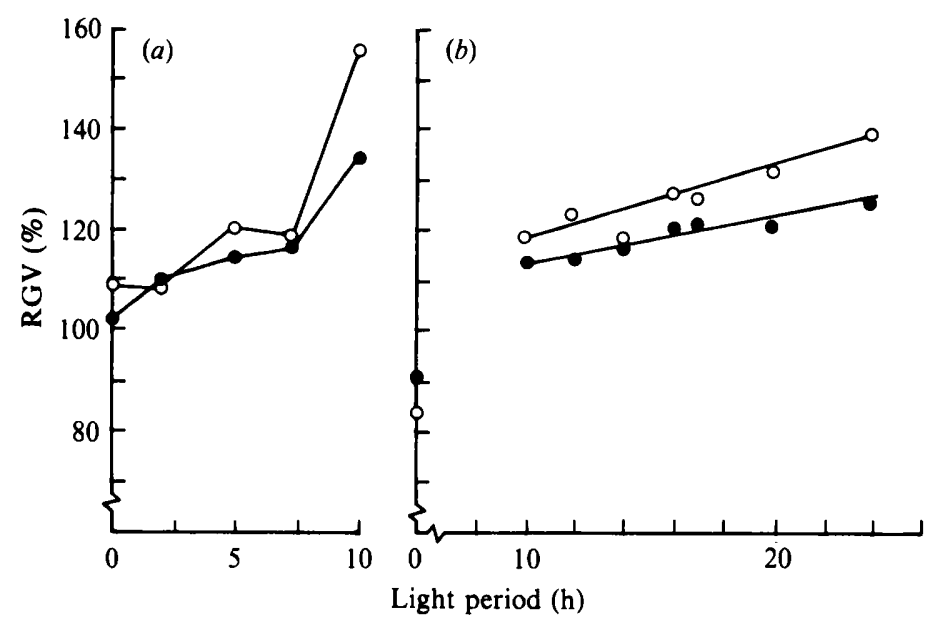

Fig. 2. Effect of illumination on gas vesicle formation after phosphate enrichment. Samples were taken from a phosphate-limited culture $\left(D=0.004 \mathrm{~h}^{-1}\right)$; following the addition of phosphate $(20 \mu \mathrm{M}$ final concentration), the subcultures were incubated in the light for the periods shown. The results are from two separate experiments. (a) RGV (percentage of the value at $t=0$ ) measured $12 \mathrm{~h}(O)$ and $41 \mathrm{~h}(\mathrm{O})$ after addition of phosphate. (b) RGV measured $24 \mathrm{~h}(O)$ and $43 \mathrm{~h}(O)$ after addition of phosphate.

the length of the light period $(P<0.01)$, and the gas vesicle volume was larger after $43 \mathrm{~h}$ $(P<0.05$, Wilcoxon's test $)$.

Although a light period of $10 \mathrm{~h}$ may be the minimum needed to stimulate gas vesicle formation in cultures with a growth rate of $0.004 \mathrm{~h}^{-1}$, it is possible that there is a specific period in which induction of gas vesicle formation can only take place if light is provided. To discriminate between these two possibilities, phosphate-limited cultures were given a $5 \mathrm{~h}$ light period at different times after the addition of phosphate (Fig. 3). As expected, little or no net gas vesicle formation was detected in the dark or when the $5 \mathrm{~h}$ light period immediately followed the phosphate pulse. If the light pulse was given between 5 and $10 \mathrm{~h}$ after the phosphate pulse, stimulation of gas vesicle formation occurred, but even greater stimulation was observed if the light pulse was given 10 or $14 \mathrm{~h}$ after phosphate enrichment. Hence, although light is necessary to induce the formation of new gas vesicles, the induction process is not always responsive to light.

\section{Influence of light intensity}

The following experiment was to determine if gas vesicle formation was dependent on light intensity. After the phosphate pulse, the cultures were kept continuously at different light intensities (Fig. 4). Gas vesicle formation increased with increasing irradiance up to $50 \mu \mathrm{mol} \mathrm{m} \mathrm{m}^{-2} \mathrm{~s}^{-1}$, decreasing slightly at higher irradiances.

\section{Effect of metabolic inhibitors}

The metabolic inhibitors chloramphenicol, which inhibits the translation of mRNA, rifampicin, which blocks transcription of DNA, and 3-(3,4-dichlorophenyl)- $N, N^{\prime}$-dimethylurea (DCMU), which inhibits photosystem II activity, all prevented gas vesicle formation in phosphate-limited cultures pulsed with phosphate (Table 1), whereas the control culture kept in the light after the phosphate pulse showed a $76 \%$ increase in relative gas vesicle content.

\section{DISCUSSION}

When sufficient phosphate for about two doublings of cell mass was added to phosphoruslimited cultures, protein synthesis started before cell division, but between 24 and $50 \mathrm{~h}$ after the 


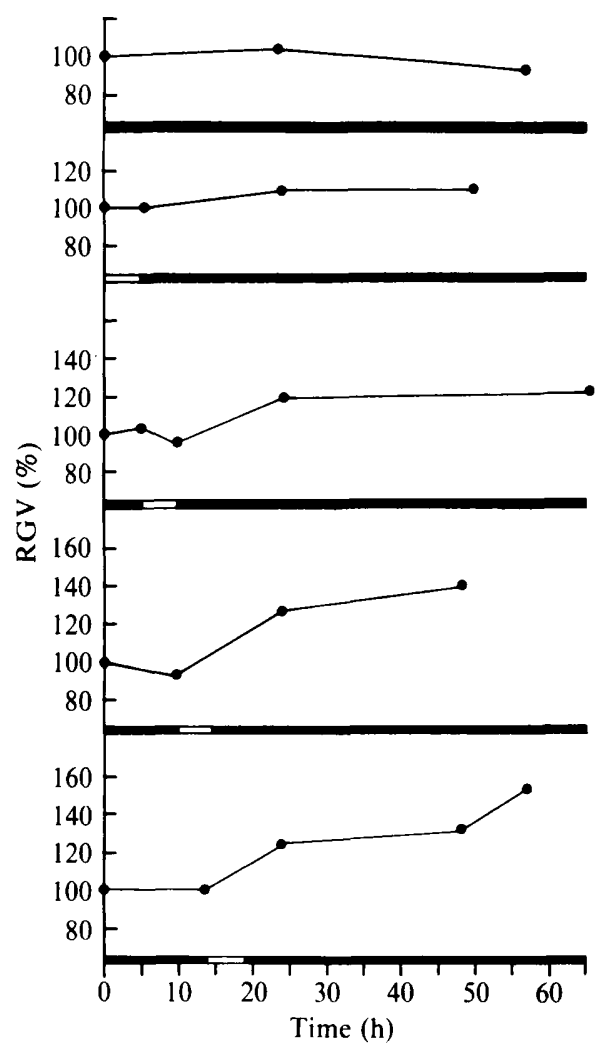

Fig. 3

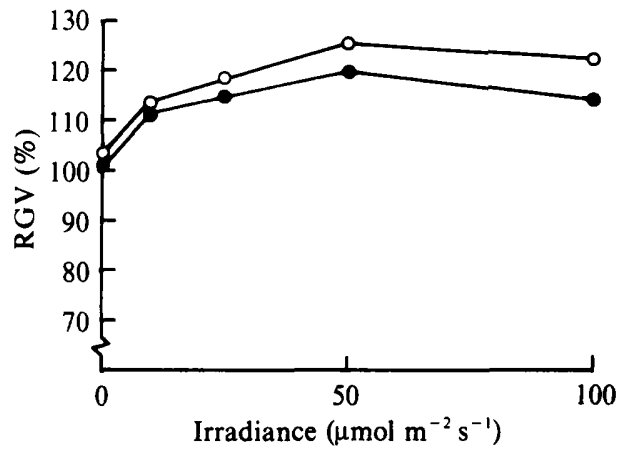

Fig. 4

Fig. 3. Effect of the time at which a $5 \mathrm{~h}$ light period was given on gas vesicle formation after phosphate was added at zero time. Samples were taken from phosphate-limited cultures of $M$. aeruginosa AK1 at $D=0.004 \mathrm{~h}^{-1}$. The white bars indicate the light period.

Fig. 4. Influence of light intensity on gas vesicle formation after giving a phosphate pulse at zero time to samples taken from phosphate-limited cultures $\left(D=0.004 \mathrm{~h}^{-1}\right)$ of $M$. aeruginosa AK1. RGV $14 \mathrm{~h}$ $(O)$ and $40 \mathrm{~h}(\mathrm{O})$ after addition of phosphate is shown.

phosphate pulse all the cultures kept in continuous light synthesized protein at the same rate of $0.020 \mathrm{~h}^{-1}$. The rate of gas vesicle formation in the two cultures with the lower dilution rates exceeded the synthesis rates of other cell proteins, resulting in an increase in the cellular gas vesicle content. In the culture with the highest dilution rate no increase in RGV was observed after the phosphate pulse, except in the culture which only received $5 \mathrm{~h}$ of light immediately after the phosphate pulse. We suggest that this increased content was temporary because there was no significant difference in gas vacuolation between steady-state phosphate-limited and light-limited cultures of $M$. aeruginosa. We do not know whether the observed effect of relieving the limitation is specific for phosphate. If similar formation of gas vesicles were to occur after nitrogen enrichment of nitrogen-limited gas-vacuolate cyanobacteria, it might partly explain the increase in buoyancy and accumulation of filaments of Oscillatoria agardhii var isothrix in the surface layers of Deming Lake, Minnesota after nitrogen enrichment (Klemer, 1976). Klemer (1978) reported an initial increase in relative gas vacuolation after an increase in nitrogenlimited dilution rate. However, this reported increase in RGV can also be explained by a decrease in the polysaccharide ballast (see Konopka et al. 1987a).

All the present experiments showed that the formation of gas vesicle protein is light dependent. Maximal formation occurred if a light pulse was given at least $10 \mathrm{~h}$ after the phosphate pulse. These cultures showed a higher rate of increase in RGV during the first $12 \mathrm{~h}$ 
Table 1. Influence of metabolic inhibitors on the formation of gas vesicles after supplying a phosphate pulse to a phosphate-limited culture of $M$. aeruginosa $A K 1$, growing at $D=0.004 h^{-1}$

The cultures received a photon flux density of approximately $100 \mu \mathrm{mol} \mathrm{m}^{-2} \mathrm{~s}^{-1}$.

\begin{tabular}{lccc}
\multirow{2}{*}{ Inhibitor } & $\begin{array}{c}c \\
\text { Concn } \\
(\mu \mathrm{M})\end{array}$ & $\overbrace{24 \mathrm{~h}}^{\mathrm{RGV}^{*}}$ & $48 \mathrm{~h}$ \\
Rifampicin & $0 \dagger$ & - & 97 \\
& $1 \cdot 25$ & - & 99 \\
Chloramphenicol & $2 \cdot 50$ & - & 99 \\
& $0 \dagger$ & 97 & - \\
DCMU & 50 & 97 & - \\
& 100 & 100 & - \\
& $0 \dagger$ & 95 & 95 \\
& $0 \ddagger$ & - & 176 \\
& 10 & 98 & 96 \\
& 100 & 98 & 98
\end{tabular}

- , Not determined.

* RGV, relative gas vesicle content, expressed as a percentage of the RGV at the start of the experiment.

$\dagger$ Control cultures kept in the dark after the phosphate pulse.

$\ddagger$ Control culture kept in the light after the phosphate pulse.

than during the following $36 \mathrm{~h}$ (Fig. 3), whereas the cultures kept in continuous light after phosphate enrichment showed a linear increase in RGV. Similar results were found by Lehmann \& Jost (1971) for another strain of $M$. aeruginosa; these authors speculated that the first rapid increase might reflect the synthesis of the conical ends of the gas vesicle, and that the second, slower phase might be caused by elongation of the newly initiated gas vesicles. In our experiments, white light with a photon irradiance of $50 \mu \mathrm{mol} \mathrm{m}^{-2} \mathrm{~s}^{-1}$ was enough to saturate the rate of formation. The inhibition by DCMU suggests the involvement of photosystem II (providing reductant or fixed carbon) in the synthesis of gas vesicle protein. From the observed inhibition by chloramphenicol and rifampicin, we conclude that the formation of gas vesicles requires de novo protein synthesis.

Konopka et al. (1975) observed that in cells of the heterotrophic bacterium Ancylobacter (Microcyclus) aquaticus treated with chloramphenicol the gas vacuole volume decreased substantially as a consequence of a decrease in the average size of the gas vesicles. This was interpreted as indicating that gas vesicles were in a dynamic state, i.e. there was a continuous turnover of the gas vesicle. The cyanobacterium Nostoc muscorum PCC 6719 also showed reduced gas vesicle volume during chloramphenicol treatment (Armstrong et al., 1983). However, in this organism the chloramphenicol treatment caused a rise in turgor pressure and the loss in gas vesicle volume was caused by turgor-induced collapse. This did not occur in our experiments, as $M$. aeruginosa possesses gas vesicles too strong to be collapsed by turgor pressure (Kromkamp et al., 1988). Since no loss of gas vesicle volume was observed with the chloramphenicol or rifampicin treatments, it seems likely that the turnover rate of the gas vesicles is rather slow.

In the planktonic cyanobacteria we have studied, gas vesicles are formed constitutively. Light-limited cultures of Aphanizomenon flos-aquae PCC 7905 grown in light-dark cycles decreased their gas vesicle content as the growth rate increased, due to differences in the rates of total protein synthesis and gas vesicle protein synthesis (Kromkamp et al., 1986), and not by destruction of existing gas vesicles by turgor pressure as suggested for $N$. muscorum PCC 6719 by Armstrong et al. (1983). Phosphate-limited cultures of Aphanizomenon flos-aquae, however, showed a constant gas vesicle volume with varying phosphate-limited growth rate (Konopka et $a l ., 1987 a$ ). In this organism there appeared to be a delay in changing the rate of gas vesicle formation when culture conditions changed, because when a light-limited culture was transferred to a higher light intensity it took more than one generation time before the rate of gas 
vesicle formation altered. Light-limited cultures of $M$. aeruginosa AK1 showed a constant gas vesicle volume with different light-limited growth rates, and when the growth rate was increased, the rate of gas vesicle protein synthesis equalled the total rate of protein synthesis, as no change in net gas vacuolation was observed during the transient state (Kromkamp et al., 1988). Those results implied that a constant amount of gas vesicles per unit of cell protein was constitutively synthesized. The results presented in this report, however, show that regulation of gas vesicle formation is more complex and changes can occur quite rapidly. Rapid change of gas vesicle content has only been reported in hormogonia of the cyanobacteria $N$. muscorum PCC 6719 and Calothrix PCC 7601. The vegetative filaments of these organisms do not contain gas vesicles, and their subsequent formation has been interpreted as a way of facilitating dispersal, as it results in buoyant hormogonia (Armstrong et al., 1983; Damerval et al., 1987).

We would like to thank A. E. Walsby and P. K. Hayes for valuable suggestions on the manuscript.

\section{REFERENCES}

Armstrong, R. E., Hayes, P. K. \& Walsby, A. E. (1983). Gas vacuole formation in hormogonia of Nostoc muscorum. Journal of General Microbiology 129, 263-270.

Damerval, T., Houmard, J., Guglielmi, G., Csizar, K. \& TANDeau de Marsac, N. (1987). A developmentally regulated gvp $A B C$ operon is involved in the formation of gas vesicles in the cyanobacterium Calothrix 7601. Gene 54, 83-92.

HAYES, P. K. \& Walsby, A. E. (1984). An investigation into the recycling of gas vesicle protein derived from collapsed gas vesicles. Journal of General Microbiology 130, 1591-1596.

Herbert, D., Phipps, P. J. \& Strange, R. W. (1971). Chemical analyses of microbial cells. Methods in Microbiology 5B, 209-344.

JoNEs, D. D. \& JosT, M. (1970). Isolation and chemical characterization of gas-vacuole membranes from Microcystis aeruginosa Kuetz emend. Elenkin. Archiv für Mikrobiologie 70, 43-64.

KLEMER, A. R. (1976). The vertical distribution of Oscillatoria agardhii var. isothrix. Archiv für Hydrobiologie 78, 343-362.

KLEMER, A. R. (1978). Nitrogen limitation of growth and gas vacuolation in Oscillatoria rubescens. Verhandlungen der Internationalen Vereinigung für theoretische und angewandte Limnologie 20, 2293-2297.

Konopka, A. E., Staley, J. T. \& LaRa, J. C. (1975). Gas vesicle assembly in Microcyclus aquaticus. Journal of Bacteriology 122, 1301-1309.

Konopka, A., Lara, J. C. \& Staley, J. T. (1977). Isolation and characterization of gas vesicles from Microcyclus aquaticus. Archives of Microbiology 112, 133-140.

Konopka, A., Kromkamp, J. \& MUR, L. R. (1987a). Regulation of gas vesicle content and buoyancy in light- or phosphate-limited cultures of Aphanizomenon flos-aquae (Cyanophyceae). Journal of Phycology 23, 70-78.

KonopKa, A., Kromkamp, J. C. \& MUR, L. R. (1987b). Buoyancy regulation in phosphate-limited cultures of Microcystis aeruginosa. FEMS Microbiology Ecology 45, 135-142.

KROMKaMP, J. C. \& MUR, L. R. (1984). Buoyant density changes in the cyanobacterium Microcystis aeruginosa due to changes in the cellular carbo- hydrate content. FEMS Microbiology Letters 25, 105-109.

Kromkamp, J., KonopkA, A. \& MUR, L. R. (1986). Buoyancy regulation in a strain of Aphanizomenon flos-aquae (Cyanophyceae): the importance of carbohydrate accumulation and gas vesicle collapse. Journal of General Microbiology 132, 2113-2121.

Kromkamp, J., KonopKa, A. \& MUR, L. R. (1988). Buoyancy regulation in light-limited continuous cultures of Microcystis aeruginosa. Journal of Plankton Research 10, 171-183.

LehmanN, H. \& Jost, M. (1971). Kinetics of the assembly of gas vacuoles in the blue-green alga Microcystis aeruginosa Kuetz emend. Elenkin. Archiv für Mikrobiologie 79, 59-68.

OLIVER, R. L. \& WALSBY, A. E. (1984). Direct evidence for the role of light-mediated gas-vesicle collapse in the buoyancy regulation of Anabaena flos-aquae (cyanobacteria). Limnology and Oceanography 29, 879-886.

RAJ, A. D. (1983). Proposal of Ancylobacter, gen. nov., as a substitute for the bacterial genus Microcyclus Orskov 1928. International Journal of Systematic Bacteriology 33, 397-398.

WAALAND, J. R. \& BRANTON, D. (1969). Gas vacuole development in a blue-green alga. Science 163, 13391341 .

Walker, J. E. \& Walsby, A. E. (1983). Molecular weight of gas-vesicle protein from the planktonic cyanobacterium Anabaena flos-aquae and implications for the structure of the vesicles. Biochemical Journal 209, 809-815.

WalsBY, A. E. (1973). A portable apparatus for measuring relative gas vacuolation, the strength of gas vacuoles and turgor pressure in planktonic bluegreen algae and bacteria. Limnology and Oceanography 18, 653-658.

WALSBY, A. E. (1982). The elastic compressibility of gas vesicles. Proceedings of the Royal Society London B216, 335-368.

WALSBY, A. E. \& BuCKLAND, B. (1969). Isolation and purification of intact gas vesicles from a blue-green alga. Nature, London 224, 716-717.

ZeHNDER, A. \& Hughes, E. O. (1958). The anti-algal activity of actidione. Canadian Journal of Microbiology 4, 399-408. 